\title{
SPECTRUM OF CARCINOMA GALLBLADDER
}

\author{
Rajesh Kumar Maurya ${ }^{1}$, Raj Kumar Singh², Krishna Bahaddur Mishra ${ }^{3}$, Ruby Singh ${ }^{4}$ \\ ${ }^{1}$ Associate Professor, Department of Surgery, GSVM Medical College, Kanpur. \\ ${ }^{2}$ Associate Professor, Department of Surgery, GSVM Medical College, Kanpur. \\ ${ }^{3}$ Professor, Department of Surgery, GSVM Medical College, Kanpur. \\ 4 Junior Resident, Department of Surgery, GSVM Medical College, Kanpur.
}

ABSTRACT
BACKGROUND
Carcinoma of gallbladder is uncommon but is a highly fatal malignancy due to late presentation. However, it is the most common
malignancy of biliary tract and represents $80-90 \%$ of the biliary tract complications. The northern parts of India has high incidence
of gallbladder stone disease with a rising trend in gallbladder malignancy.

\section{MATERIALS AND METHODS}

A total of 90 cases who reported to Department of Surgery, GSVM Medical College. Kanpur \& J K Cancer Institute, Kanpur from January 2015 to June 2016 were included in this study. The trend and its magnitude were analysed.

\section{RESULTS}

$35.5 \%$ cases were in sixth decade of life while $31.11 \%$ were in fifth decade. The male to female ratio was $2.1: 1.75 .55 \%$ presented with abdominal lump and $22 \%$ with ascites at the time of presentation.

\section{CONCLUSION}

Carcinoma of gallbladder is a silent progressive disease with increasing risks in late presentation. Ultrasound screening may be a valuable tool for an early diagnosis, mainly where there are high incidences of gallstone disease.

\section{KEYWORDS}

Gallbladder, Malignancy, Icterus, Pain.

HOW TO CITE THIS ARTICLE: Maurya RK, Singh RK, Mishra KB, et al. Spectrum of carcinoma gallbladder. J. Evolution Med. Dent. Sci. 2017;6(69):4903-4905, DOI: 10.14260/Jemds/2017/1063

\section{BACKGROUND \\ Gallbladder cancer is uncommon but a highly fatal malignancy. However, gallbladder cancer is the most common malignancy of the biliary tract representing $80 \%-90 \%$ of biliary tract cancers worldwide according to autopsy study. \\ Around 5000 new cases are diagnosed each year in USA. The worldwide incidence varies as per geographic location. High rates are seen in South American countries, particularly Chile, Bolivia, Ecuador, as well as some parts of India, Pakistan, Korea and Japan. ${ }^{1,2}$ \\ Gallbladder cancer is the most common of all abdominal malignancies in Northern part of India. An incidence rate of 4.5 and $10 \%$ per $1,00,000$ noted in males and females respectively. \\ $80 \%$ cases of gallbladder cancer are associated with gall stone disease and 7-20\% were porcelain gallbladder cases.}

\section{Aims \& Objectives}

1. Study of trend and magnitude of carcinoma of gallbladder in Kanpur and surrounding districts.

2. Study of risk factor of carcinoma of gallbladder in in Kanpur and surrounding districts.

Financial or Other, Competing Interest: None.

Submission 02-06-2017, Peer Review 28-06-2017,

Acceptance 03-07-2017, Published 28-08-2017.

Corresponding Author:

Krishna Bahaddur Mishra,

Professor, Department of Surgery,

GSVM Medical College, Kanpur.

E-mail: kbm.mishra@gmail.com

DOI: $10.14260 /$ jemds $/ 2017 / 1063$

\section{MATERIALS \& METHODS}

Present descriptive study was carried out in the Department of Surgery, GSVM Medical College, Kanpur, UP, India.

\section{Cases}

All consecutive newly diagnosed patients with GBC (outpatients \& inpatients from January 2015 to June 2016) reporting in Department of Surgery, GSVM Medical College, Kanpur as well as from J K Cancer Institute, Kanpur were included.

\section{Diagnosis of GBC}

The diagnosis of gallbladder cancer (GBC) was made on the basis of ultrasound CT and MRI findings, imaging features and was confirmed by histology (if the patient was found to be inoperable based on imaging studies).

\section{Criteria for Diagnosis}

1. Clinical.

2. USG, CT \& MRI.

3. Gallbladder wall thickness.

4. Liver infiltration, Jaundice \& Lymph node.

\section{Inclusion Criteria}

Consecutive patients with GBC who were in sufficiently good physical and mental health to give reliable answers to the questionnaire were included in the study.

\section{Exclusion Criteria}

- Patients with any other major comorbid illness.

- Refusal to participate in the study. 


\section{RESULTS}

These patients were mainly from Kanpur and surrounding areas. The patients' data were analysed $\&$ results are given in the following tables.

\begin{tabular}{|c|c|c|}
\hline Age Group & No. of Cases & Percentage \\
\hline $21-30$ & 00 & 00 \\
\hline $31-40$ & 06 & 6.66 \\
\hline $41-50$ & 24 & 26.67 \\
\hline $51-60$ & 32 & 35.55 \\
\hline 61 and above & 28 & 31.11 \\
\hline Total & 90 & 100 \\
\hline
\end{tabular}

In our study of 90 cases, we found $35.5 \%$ cases in the sixth decade (51-60 years). The second largest group $(31.11 \%)$ was from $5^{\text {th }}$ and $7^{\text {th }}$ decade.

\begin{tabular}{|c|c|c|}
\hline Age group & Male & Female \\
\hline $21-30$ & 0 & 0 \\
\hline $31-40$ & 0 & 6 \\
\hline $41-50$ & 7 & 17 \\
\hline $51-60$ & 9 & 23 \\
\hline 61 and above & 13 & 15 \\
\hline Total & $\mathbf{2 9}$ & $\mathbf{6 1}$ \\
\hline \multicolumn{2}{|c|}{ Table 2. Sex Distribution } \\
\hline
\end{tabular}

Female to male ratio was $2.1: 1$ according to the above table. 61 patients out of the 90 cases were female. It shows high prevalence of gallbladder cancer in elderly females mostly above 40 years of age.

\begin{tabular}{|c|c|c|}
\hline Symptoms & No. of cases & Percentage (\%) \\
\hline Abdominal pain & 71 & 78.88 \\
\hline Weight loss & 46 & 51.11 \\
\hline Nausea & 34 & 37.77 \\
\hline Pruritus & 23 & 25.55 \\
\hline Fever & 10 & 11.11 \\
\hline \multicolumn{2}{|c|}{ Table 3. Distribution of Symptoms } \\
\hline
\end{tabular}

Pain in abdomen was the most common symptom and was present in $78.88 \%$ of cases. Jaundice and weight loss were present in significant proportion of cases.

\begin{tabular}{|c|c|c|}
\hline Signs & No. of cases & Percentage \\
\hline Abdominal lump & 68 & 75.55 \\
\hline Tenderness & 38 & 42.22 \\
\hline Icterus & 40 & 44.44 \\
\hline Ascites & 20 & 22.22 \\
\hline \multicolumn{2}{|c|}{ Table 4. Distribution of Signs } \\
\hline
\end{tabular}

$75.55 \%$ of the cases presented with abdominal lump, second most common sign was tenderness in abdomen and icterus. Ascites was present in approx. $22 \%$ cases.

\begin{tabular}{|c|c|c|}
\hline Socioeconomic class & No. of cases & Percentage \\
\hline Upper & 0 & 0 \\
\hline Upper middle & 6 & 6.66 \\
\hline Lower middle & 5 & 5.55 \\
\hline Upper lower & 14 & 15.55 \\
\hline Lower & 65 & 72.22 \\
\hline \multicolumn{2}{|c|}{ Table 5. Socioeconomic Status } \\
\end{tabular}

$72 \%$ of the cases belonged to lower socioeconomic class (Kuppuswamy) and $15.55 \%$ belonged to upper lower class. Only $6.66 \%$ and $5.55 \%$ patients belonged to upper middle and lower middle class.

\begin{tabular}{|c|c|c|}
\hline Duration & No. of Cases & Percentage \\
\hline$<1$ month & 0 & 0 \\
\hline 1-3 months & 22 & 24.44 \\
\hline $3-6$ months & 57 & 63.33 \\
\hline 6 m - 1 year & 7 & 7.78 \\
\hline$>1$ year & 4 & 4.44 \\
\hline Total & $\mathbf{9 0}$ & $\mathbf{1 0 0}$ \\
\hline \multicolumn{2}{|c|}{ Table 6. Duration of Symptoms } \\
\hline
\end{tabular}

Most of the patients i.e. 88\% (79 out of 90) had duration of symptoms less than six months. Only $12 \%$ of the patients had symptoms for more than 6 months.

\begin{tabular}{|c|c|c|}
\hline Characteristics & No. of Cases & Percentage \\
\hline Vegetarian & 43 & 47.78 \\
\hline Non-vegetarian & 47 & 52.22 \\
\hline Mustard oil users & 70 & 77.77 \\
\hline Refined oil users & 20 & 22.22 \\
\hline \multicolumn{2}{|c|}{ Table 7. Relationship with Dietary Habits } \\
\hline
\end{tabular}

$52.22 \%$ of patients were non-vegetarian and almost all other patients used mustard oil as cooking medium.

\begin{tabular}{|c|c|c|}
\hline Variable & No. of Cases & Percentage \\
\hline History of Typhoid & 40 & 44.44 \\
\hline Family history of Ca GB & 17 & 18.88 \\
\hline $\begin{array}{c}\text { Cholelithiasis associated with } \\
\text { Ca GB }\end{array}$ & 73 & 81.11 \\
\hline \multicolumn{2}{|c|}{ Table 8. History of Past or Present Illness } \\
\hline
\end{tabular}

40 patients $(44.44 \%)$ had past history of Typhoid and $81 \%$ of the patients had gallbladder stones.

\begin{tabular}{|c|c|c|}
\hline Lab Parameter & Mean & Range \\
\hline $\mathrm{Hb}(\mathrm{g} / \mathrm{dL})$ & 8.1 & $4.2-12.8$ \\
\hline S. bilirubin $(\mathrm{mg} / \mathrm{dL})$ & 2.8 & $0.4-25.3$ \\
\hline $\mathrm{S}$. ALP (IU/L) & 938.6 & $79.0-2255.0$ \\
\hline Total Protein (g/dL) & 6.9 & $4.8-8.3$ \\
\hline S. Albumin (g/dL) & 3.5 & $1.9-5.2$ \\
\hline \multicolumn{2}{|c|}{ Table 9. Lab Parameters of the Patients in the Study } \\
\hline
\end{tabular}

Mean $\mathrm{Hb}$ of the patients was 8.1 and ranged from 4.2 $12.8(\mathrm{~g} / \mathrm{dL})$. Maximum bilirubin level observed was 25.3 $(\mathrm{mg} / \mathrm{dL})$.

\begin{tabular}{|c|c|c|}
\hline BMI & No. of Cases & Percentage \\
\hline$<24\left(\mathrm{~kg} / \mathrm{m}^{2}\right)$ & 17 & 18.88 \\
\hline $24-25$ & 7 & 7.78 \\
\hline $26-28$ & 39 & 43.33 \\
\hline$>28$ & 27 & 30 \\
\hline Total & $\mathbf{9 0}$ & $\mathbf{1 0 0}$ \\
\hline \multicolumn{2}{|c|}{ Table 10. Body Mass Index $\left.\mathbf{~} \mathbf{k g} / \mathbf{m}^{2}\right)$} \\
\hline
\end{tabular}

$73 \%$ of the patients had BMI $>25\left(\mathrm{~kg} / \mathrm{m}^{2}\right)$. Gallbladder cancer is prevalent in patients having higher BMI.

\begin{tabular}{|c|c|c|}
\hline Tobacco chewer & 48 & 53.33 \\
\hline Cigarette smoking & 21 & 23.33 \\
\hline Alcohol consumption & 13 & 14.44 \\
\hline \multicolumn{2}{|c|}{ Table 11. Tobacco and Alcohol Consumption } \\
\hline
\end{tabular}

$53 \%$ patients are tobacco chewers while smoking and alcohol consumption is found in $23 \%$ and $14 \%$ respectively. 


\section{DISCUSSION}

\section{Hospital-based Prevalence}

The total number of registries of all types of cancers in Department of Surgery, LLRH \& JK Cancer Institute from January 2015 to June 2016 are 25797, out of which 90 cases are of carcinoma gallbladder.

So the hospital-based incidence showing magnitude of Ca GB is $(90 / 25797 \times 1000) 3.49$ per 1000 cancer cases at Kanpur.

Results from this study shows that gallbladder cancer is predominantly a disease of elderly females; with an overall female to male ratio of 1.2:1. These results are consistent with the results of other studies as well.3,4

There is a direct link between gallstones and Carcinoma gallbladder.5,6 In patients with Carcinoma gallbladder, the incidence of cholelithiasis ranges from $54 \%$ to $97 \%$. Carcinoma gallbladder is more common in patients with Mirizzi's syndrome and typhoid carriers are a high-risk group. Moreover, porcelain (calcified) gallbladder has a high malignant potential and large, sessile polyps (more than 10 $\mathrm{mm}$ ) are more likely to be malignant than multiple, small, pedunculated ones.7,8 Polyps over $18 \mathrm{~mm}$ must be removed, as they are likely malignant. Approximately, $60 \%$ of tumours originate in the fundus of the gallbladder, $30 \%$ originate in the body, and $10 \%$ originate in the neck.

Gallbladder Cancer presents early in females (51 to 60 years) than males (61 years of age). Similar results were observed in other studies from India. ${ }^{3}$

Typhoid carrier state was found to be one of the important risk factors for the development of GB cancer in the current study. Chronic S. typhi infection can be carried in the GB. Several other studies also suggested an association between GB cancer and typhoid carrier state.9,10 However, the association found in the current study can be only suggestive and was not confirmed by the serological examination.

In our study, most of the patients belonged to lower and upper lower socioeconomic status. There were $72.2 \%$ cases. It is reported that metabolic and lifestyle factors including obesity, dietary habits, infection and parity also contribute to the occurrence of gallbladder cancer.

The association of cholelithiasis with gallbladder carcinoma is very strong.6,11 The gallstones are the commonest factor leading to gallbladder carcinogenesis. ${ }^{11}$

Signs of malignant disease on ultrasound examination include discontinuous mucosa, echogenic mucosa, and submucosal echolucency. ${ }^{12}$ Diffuse thickening of the gallbladder is also common in gallbladder cancer but is also found in benign condition.

Serum carcinoembryonic antigen (CEA) greater than 4 $\mathrm{ng} / \mathrm{mL}$ is 93 percent specific and 50 percent sensitive for detecting gallbladder cancer in the presence of appropriate symptoms.

A magnetic resonance (MR) scan with MR cholangiography is an ideal study.

The role of dietary factors in gallbladder carcinogenesis is now well defined. But in our study, we found non-vegetarians more prone to GBC than vegetarians. This could be due to the protective effect of vegetables on gallbladder carcinogenesis while consumption of red meat was associated with increased risk of gallbladder cancer. ${ }^{4}$

The study of was consistent with our finding that the consumption of carcinogenic impurities in mustard oil may contribute to elevated incidence of gallbladder cancer in North India. ${ }^{13}$

\section{CONCLUSION}

Carcinoma gallbladder is a silent progressive disease with most of the patients presenting in an advanced stage. There is a neglect in surgical treatment of gallstone disease in spite of better imaging facilities and surgical facilities.

Due to lack of awareness, poor economic status, the rural population presents with deep jaundice and a non-resectable disease. Carcinoma gallbladder is on the rise in Kanpur area, but much could not be offered to the patients due to late presentation.

Ultrasound screening programme may be considered for its role in early diagnosis of gallbladder malignancy. It is worth studying as there are increasing incidences, mainly in northern India.

\section{REFERENCES}

[1] Strom BL, Soloway RD, Rios-Dalenz JL, et al. Risk factors for gallbladder cancer. An international collaborative case-control study. Cancer 1995;76(10):1747-56.

[2] Randi G, Franceschi S, La Vecchia C. Gallbladder cancer worldwide: geographical distribution and risk factors. Int J Cancer 2006;118(7):1591-602.

[3] Shukla VK, Khandelwal C, Roy SK, et al. Primary carcinoma of the gallbladder: a review of a 16-year period at the University hospital. I Surg Oncol 1985;28(1):32-5.

[4] Pandey M, Shukla VK. Diet and gallbladder cancer: a case control study. Eur J Cancer Prey 2002;11(4): 365-8.

[5] Cirillo DJ, Wallace RB, Rodabough RJ, et al. Effect of estrogen therapy on gallbladder disease. JAMA 2005;293(3):330-9.

[6] Baskaran V, Vij U, Sahni P, et al. Do the progesterone receptors have a role to play in gallbladder cancer. Int J Gastointest Cancer 2005;35(1):61-8.

[7] Csends A, Medina E, Medina A. Characteristic of the surgical procedures in Chile in different hospital. Rev Med Chile 1983;111:1065-74.

[8] Diehl AK. Epidemiology of gallbladder cancer: a synthesis of recent data. J Natl Cancer Inst 1980;65(6):1209-14.

[9] Dutta U. Gallbladder cancer: can newer insights improve the outcome? J Gastroenterol Hepatol 2012;27(4):642-53.

[10] Singh H, Pandey M, Shukla VK. Salmonella carrier state, chronic bacterial infection and gallbladder carcinogenesis. Eur J Cancer Prey 1996;5(2):144.

[11] Dutta U, Garg PK, Kumar R, et al. Typhoid carriers among patients with gallstones are at increased risk for carcinoma of the gallbladder. Am J Gastroenterol 2000;95(3):784-7.

[12] Sikora SS, Kapoor R, Pradeep R, et al. Palliative surgical treatment of malignant obstructive jaundice. Eur J Surg Oncol 1994;20(5):580-4.

[13] Misra S, Chaturvedi A, Misra NC, et al. Carcinoma of the gallbladder. Lancet Oncol 2003;4(3):167-76. 